\title{
IN-PLANE BEHAVIOUR OF AN IRON-FRAMED MASONRY FAÇADE: COMPARISON BETWEEN DIFFERENT MODELLING STRATEGIES
}

\author{
THOMAS CELANO ${ }^{1 *}$, LUCA U. ARGIENTO ${ }^{2}$, BARTOLOMEO PANTÒ ${ }^{3}$, \\ FRANCESCA CERONI ${ }^{1}$, CLAUDIA CASAPULLA ${ }^{2}$, IVO CALIÒ ${ }^{4}$, PAULO B. \\ LOURENÇO ${ }^{5}$ \\ ${ }^{1}$ Department of Engineering \\ University of Naples Parthenope \\ Centro Direzionale is.C4, 80143 Napoli, Italy \\ *e-mail: thomas.celano@uniparthenope.it \\ e-mail: francesca.ceroni@,uniparthenope.it \\ ${ }^{2}$ Department of Structure for Engineering and Architecture \\ University of Naples Federico II \\ Via Forno Vecchio, 80134 Napoli, Italy \\ e-mail: lucaumberto.argiento@unina.it \\ e-mail: casacla@unina.it \\ ${ }^{3}$ Department of Civil and Environmental Engineering, Imperial College London, \\ Exhibition Road, SW7 2AZ London, United Kingdom \\ e-mail: b.panto@imperial.ac.uk \\ ${ }^{4}$ Department of Civil Engineering and Architecture, \\ University of Catania, \\ Via Santa Sofia, 54, 95125 Catania, Italia \\ e-mail: icalio@dica.unict.it \\ ${ }^{5}$ Institute for Sustainability and Innovation in Structural Engineering (ISISE), \\ Department of Civil Engineering, University of Minho, \\ Campus de Azurém, 4800-058 Guimarães, Portugal \\ e-mail : pbl@civil.uminho.pt
}

Keywords: Historical Structures, Masonry, Metallic reinforcement, Finite Element Modelling, Discrete Macro-Element Modelling, Non-linear Static Analysis

Abstract. The 'baraccato' system is a construction technique with genius earthquake resilient features, used for the reconstruction of the historical city centres in the South of Italy after the catastrophic events occurred in the 18th-19th centuries. A very interesting example of such a building typology is represented by the Church of Santa Maria Maddalena, located in the municipality of Casamicciola Terme of the Ischia Island and built in 1896, after the 
catastrophic earthquake of 1883. The church is characterized by a mixed 'baraccato' system mainly made of yellow tuff block masonry walls strengthened by iron profiles or wooden elements. The reduced damage suffered by the church after the seismic event of 21st August 2017 evidenced the good behaviour of such a mixed structural system, especially into avoiding out-of-plane mechanisms. The presence of the iron-framed system is even more challenging in the definition of the modelling strategies for the structural analysis of the church. Thus, the choice of an appropriate numerical strategy to be used for nonlinear simulation should be properly investigated since the interaction between the frame elements and the elements representing the masonry walls has to be considered. As a first step of the structural analysis of the whole church, the in-plane behaviour of the main façade of the Church of Santa Maria Maddalena is analysed in this paper, with the aim to evaluate the efficacy of different modelling strategies. In particular, the study considers different models according to Finite and Discrete Element strategies available within DIANA FEA [1] and 3DMacro [2] software, respectively. Non-linear static analyses are carried out by means of both software and the obtained results are compared and discussed with the aim of extending them to the study of the whole church.

\section{INTRODUCTION}

After the catastrophic seismic events occurred in Southern Italy in the 18th-19th centuries, the 'baraccato' system was the most accredited construction type imposed by the kings of that time to withstand seis found throughout the in Central Asia [5]

European countries masonry. The Borbo engineering of the 18 th century. The engineers
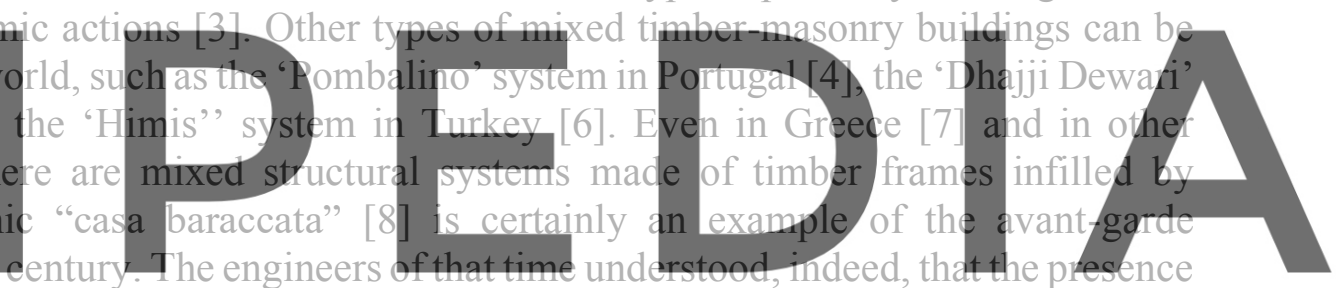

of timber frames as reinforcement elements for masonry buildings allows to obtain mixed

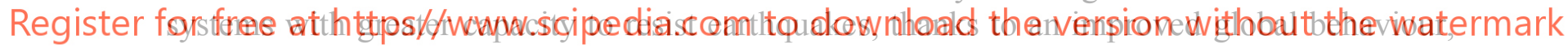
i.e. the so-called 'box-behaviour'

Recent studies on the 'baraccato' system, concerning both experimental tests and numerical modelling [9], have shown the effectiveness of the timber frames in terms of increase of dissipative and resistant capacity in comparison with unreinforced masonry structures. However, due to the high variability of the geometrical configurations, i.e. single square or rectangular modules, presence of one or two diagonals, one or more timber frames, etc., it is not possible to generalize the results for any type of 'baraccato' system. Certainly, the structural behaviour is characterized by an increase in stiffness, strength capacity and ductility. Numerical modelling of the timber-framed masonry system is, therefore, an important research topic worthy to be investigated.

Thanks to the in-situ surveys carried out after the Ischia earthquake of $21^{\text {st }}$ August 2017, several masonry structures made with a 'baraccato' system came into the light, revealing the widespread use of this earthquake-resistant system in the reconstruction of the island after the catastrophic event of 1883. In particular, in Casamicciola Terme, an extraordinary and atypical 'baraccato' system emerged in the church of Santa Maria Maddalena [10, 11]. The church was rebuilt after 1883 using a mixed timber and iron 'baraccato' masonry system, which, thus, makes it as a 'unicum'. 
This paper is focused on the study of the in-plane behaviour of the main façade of the Santa Maria Maddalena church through Finite Element and Discrete Macro-Element analyses using the software DIANA FEA and 3DMacro, respectively. In particular, pushover analyses are performed using both software, in order to compare the numerical results and suggest indications about the best modelling strategy for reliably investigating the structural behaviour of the whole church.

\section{NUMERICAL MODEL OF THE FAÇADE OF THE SANTA MARIA MADDALENA CHURCH}

\subsection{The church and the geometry of the façade}

The church of Santa Maria Maddalena was built in the Ischia Island (Napoli, Italy) soon after the catastrophic seismic event of 1883, using a mixed construction typology. As shown in Figure 1a, it can be divided into two parts: the main part was realized with an innovative iron 'baraccato' system where the masonry walls are encaged in slender iron frames, while the rear part (sacristy, priest's house, library) was made of a timber 'baraccato' system. While the timber 'baraccato' is more traditional and was diffusely used in the Ischia Island and all over the world, the other was very rare and innovative for that time, also in consideration of the more recent diffusion of iron and steel as structural elements.

The main function required to the iron-framed system was to avoid the out-of-plane mechanisms of the walls and ensure a bex-like
of such a mixed 'baradcato' system as carthqual
the seismic event of 2017 , since the damage in
the in-plane response and mainly caused
reinforcement elements (Figure 1b).

The in-plane behaviour of the iron-framed

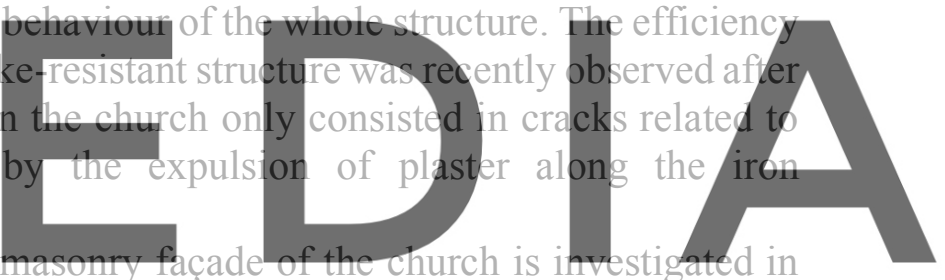

the following, starting from the description of its geometry. The façade presents a vertical

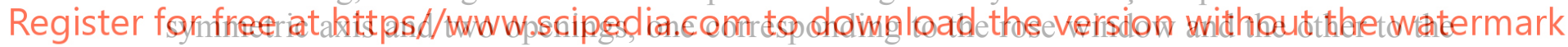
main door of the church (Figure 1c). In elevation, there are two different heights for the central nave and the side aisles. The height of the façade corresponding to the central nave is $15.9 \mathrm{~m}$ and $13.1 \mathrm{~m}$, with and without the gable, respectively, while the height of the two parts corresponding to the side aisles is $8.7 \mathrm{~m}$. The width of the central nave is equal to $9.0 \mathrm{~m}$, while the whole façade has a total length of $16.9 \mathrm{~m}$ (Figure $2 \mathrm{a}$ ).

\subsection{Materials}

The façade is characterized by a mixed 'baraccato' system made of tuff masonry strengthened by iron profiles (Figure 1d). The tuff blocks are rather regular and have dimensions of $0.27 \mathrm{~m} \times 0.23 \mathrm{~m}$ in the plane of the wall, and thickness of $0.15 \mathrm{~m}$; the stones are arranged along two faces with an internal core filled with rubble material, following the traditional technique of "sacco" masonries, with a total thickness of about $0.6 \mathrm{~m}$. The vertical iron elements are T-shaped profiles with dimensions $100 \mathrm{~mm}$ x $70 \mathrm{~mm}$ x $10 \mathrm{~mm}$, while all the other elements (horizontal and diagonal members) have a rectangular cross section with dimensions $50 \mathrm{~mm} \times 20 \mathrm{~mm}$.

Due to the lack of in-situ experimental tests on the materials used in the church, average 
values, available in the literature, are assumed in the numerical analyses for the assessment of their mechanical properties. As regards the yellow tuff blocks, a compressive strength of 1.4 $\mathrm{MPa}$ [12], a tensile strength of $0.15 \mathrm{MPa}$, a Young's modulus of $880 \mathrm{MPa}$, a Poisson's ratio of 0.2 , and a specific weight of $14 \mathrm{kN} / \mathrm{m}^{3}$ are assumed [11]. For the iron elements, a nominal strength of $235 \mathrm{MPa}$ and a Young's modulus of $153000 \mathrm{MPa}$ are assumed in agreement with the range of values reported by [13] for the wrought iron.

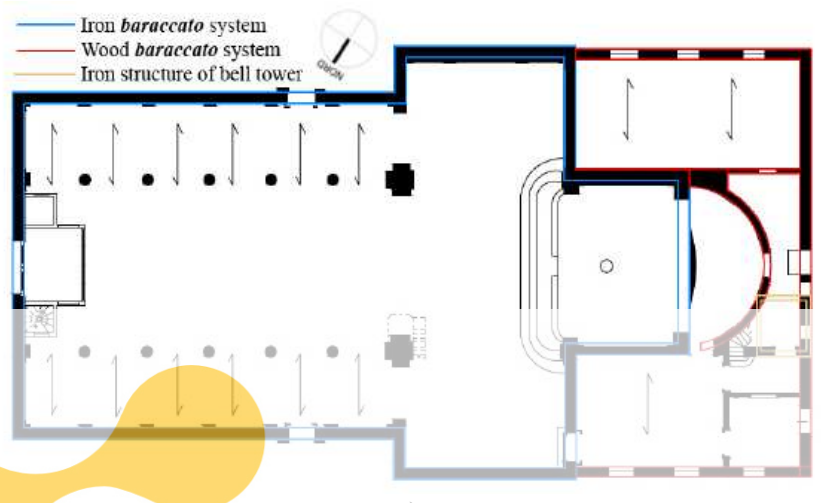

a)
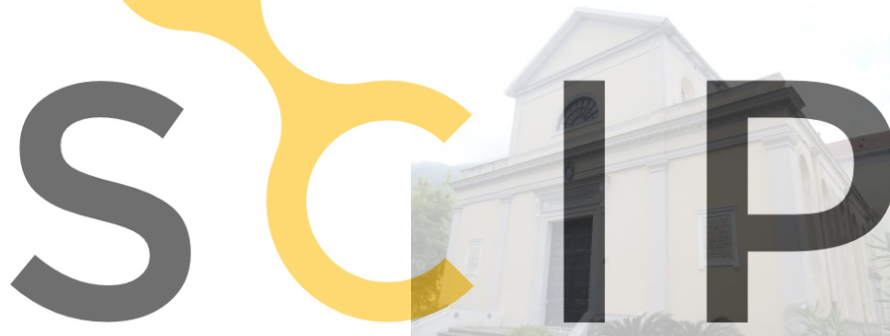

c)
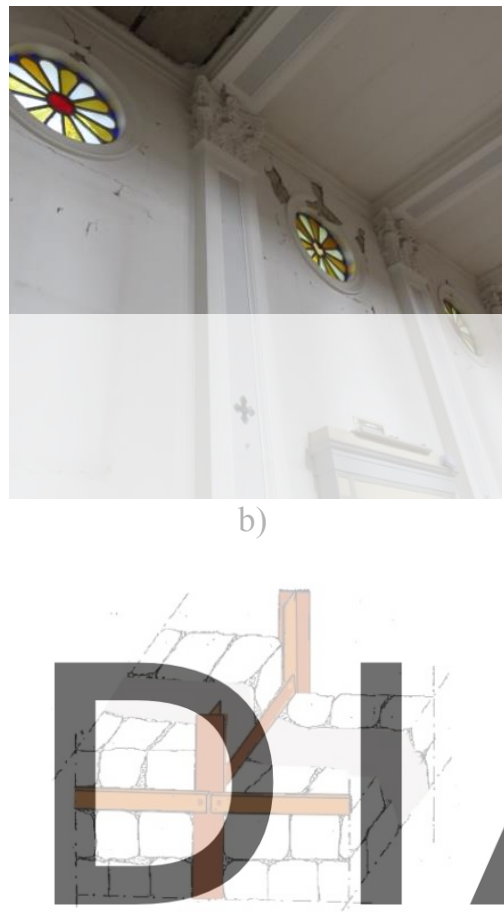

d)

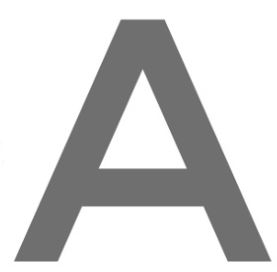

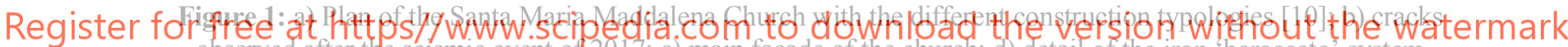
observed after the seismic event of 2017 ; c) main façade of the church; d) detail of the iron 'baraccato' system

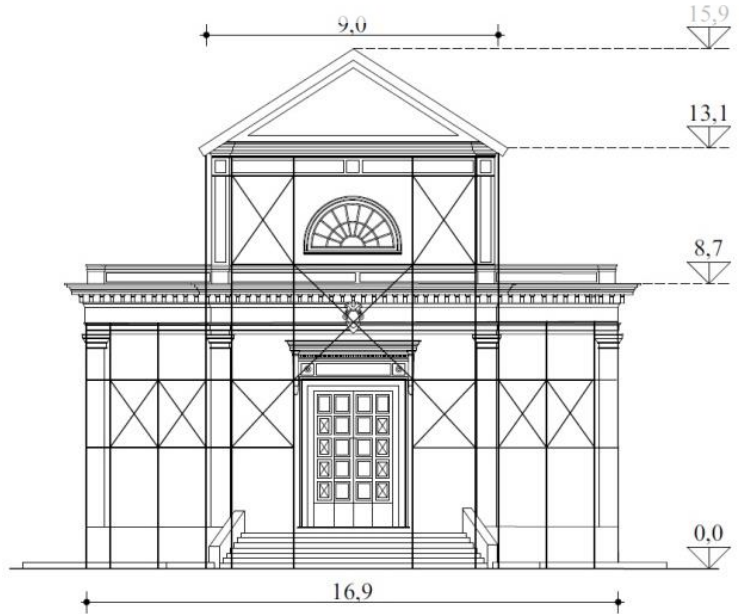

a)

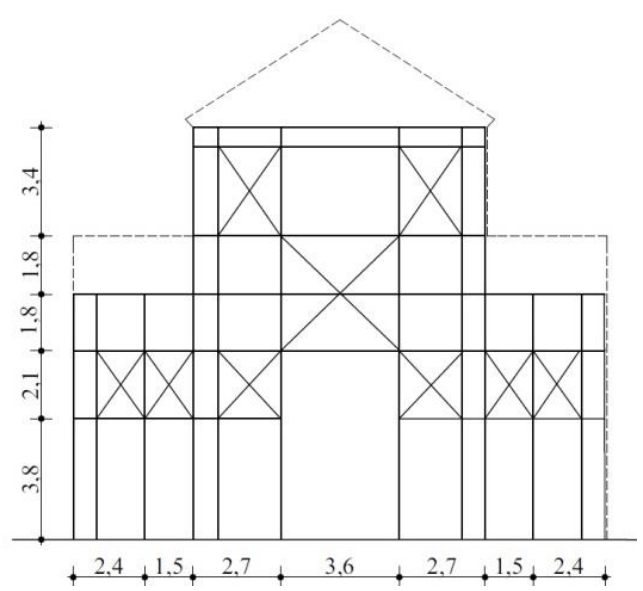

b)

Figure 2: Representation of the geometrical dimensions (in meters) of the: a) façade and b) iron frame 


\subsection{Loading conditions}

The self-weight of the façade is assumed as applied masses and the roof's loads are neglected as they are significantly lower than the self-weight of the façade (the roof trusses are, indeed, in the direction parallel to the façade). The gable is modelled as well as the remaining part of the façade without making further simplifications in the geometric model.

In general, the assessment of the seismic behaviour of buildings through non-linear analysis is based on the use of two force distributions [14]: one is proportional to the masses and the other proportional to the first vibration mode. In this particular case, the analyses evidenced that the two force distributions have a greater relevance in the lower or in the upper part of the façade, if the loads are applied proportional to the masses or to the first vibration mode, respectively. However, in this paper only the results of the non-linear static analyses carried out under the distribution of horizontal forces proportional to the masses are presented.

\subsection{Modelling strategies}

The main issues for the iron 'baraccato' system are the modelling of the iron profiles and their interaction with the masonry walls, which can be simulated with different modelling strategies. Some non-linear analyses have been performed by [15] on masonry walls strengthened with iron elements with a layout similar to that observed in the Santa Maria Maddalena church. The analyses were aimed to understand both the influence of the iron elements on the overall in-plane behaviour of the masonry walls and the influence of the

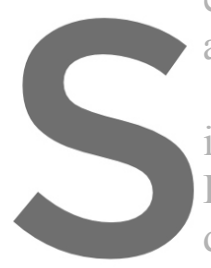
adopted modelling strat

The same two softwa in [15] are herein used for Element (FE) software discretization of the el
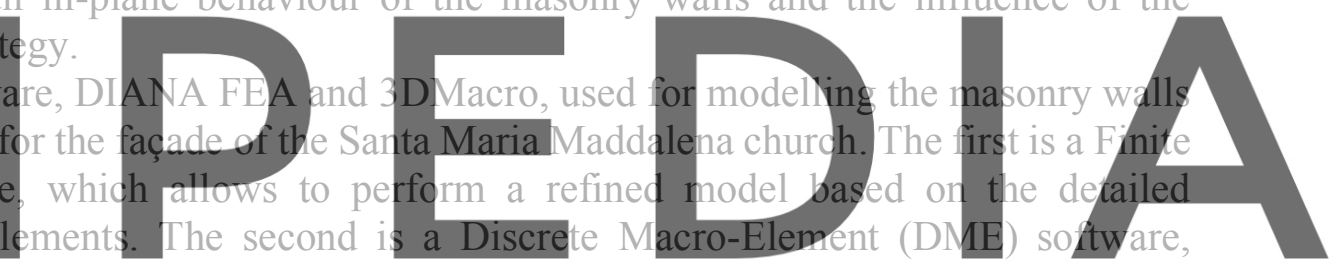
which, being based on a macro-modelling approach, adopts a great simplification of the model,

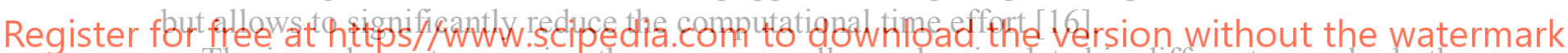
The iron elements encaging the masonry walls can be simulated in different ways by both

software. 'Beam elements' have both axial and flexural stiffness and they can guarantee or not the perfect adhesion with the solid elements simulating the masonry along the whole length. Conversely, 'truss elements' have only axial stiffness and have no adhesion with the masonry along the whole length, since the connection is active only in the end nodes of the elements. For the façade under study, two cases will be presented in the following, since they can be considered as the most representative of the real conditions of adherence between the two materials:

- Case 1: all iron elements schematized as ‘Beam' elements (BEAM model);

- Case 2: horizontal and vertical iron elements modelled as 'Beam' and diagonal elements modelled as 'Truss' (BEAM + TRUSS model).

\subsubsection{The model implemented in DIANA software}

In the FE model implemented in DIANA, the masonry is modelled by twenty-node isoparametric brick elements based on quadratic interpolation and Gauss integration, named CHX60. An optimization analysis of the size mesh was carried out providing a best value of 
$0.25 \mathrm{~m}$. The Total Strain Crack Model with an exponential law in tension (Figure 3a) and a parabolic law in compression (Figure 3b) was assumed for masonry.

For the iron profiles, the 'Beam' element, CL18B, is a three-node element, while the 'truss' element, L2TRU, is a two-node directly integrated (1-point) element. A uniaxial elastic-plastic law was assumed in tension for iron, while, in compression, the stress was limited in the elastic field to the buckling value assuming, thus, a brittle model (Figure $3 \mathrm{c}$ ).

The values of the mechanical properties used in DIANA for the materials are listed in Table 1. Lacking detailed information, the common value $G_{t}=0.012 \mathrm{~N} / \mathrm{mm}$ was used for the fracture energy in tension, as suggested in [17]. For the fracture energy in compression, the following formulation valid for $f_{c}<12 \mathrm{MPa}$ [17] was adopted:

$$
G_{c}=\left(2.8-0.1 \cdot f_{c}\right) \cdot f_{c}
$$

which has a dimension of $\mathrm{N} / \mathrm{mm}$ and where $f_{c}$ is the compressive strength of the masonry expressed in $\mathrm{N} / \mathrm{mm}^{2}$

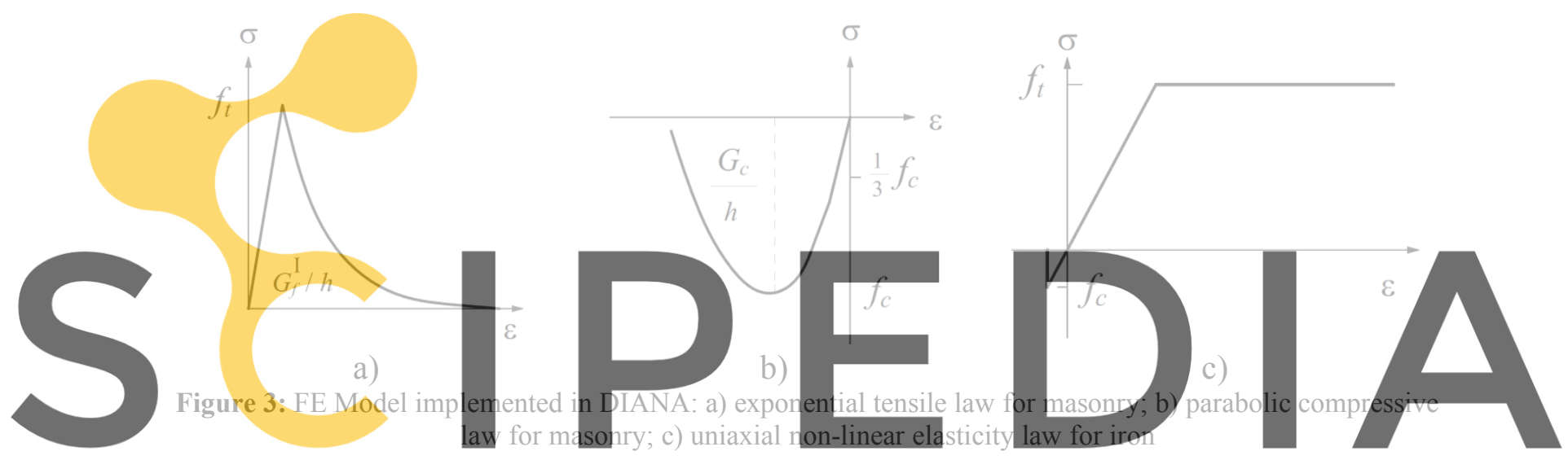

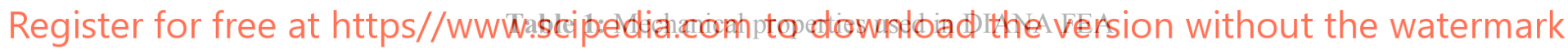

\begin{tabular}{lcccc}
\hline Parameter & & & Masonry & Iron \\
\hline Young's modulus & $E$ & {$[\mathrm{MPa}]$} & 880 & 153000 \\
\hline Poisson's ratio & $v$ & - & 0.15 & 0.3 \\
\hline Compressive strength & $f_{c}$ & {$[\mathrm{MPa}]$} & 1.4 & 15.1 \\
\hline Tensile strength & $f_{t}$ & {$[\mathrm{MPa}]$} & 0.15 & 235 \\
\hline Compressive fracture energy & $G_{c}$ & {$[\mathrm{~N} / \mathrm{mm}]$} & 3.724 & - \\
\hline Tensile fracture energy & $G_{t}$ & {$[\mathrm{~N} / \mathrm{mm}]$} & 0.012 & - \\
\hline
\end{tabular}

\subsubsection{The model implemented in 3DMacro}

The Discrete Macro-Element Model (DMEM), implemented in the software 3DMacro, considers the masonry structure as an assemblage of macro-elements [18]. According to this modelling approach, the in-plane behaviour of a masonry panel can be analyzed by means of a two-dimensional macro-element made of four hinges connecting fours rigid edges and two diagonal non-linear springs [19]. The activation of the shear-sliding and flexural failures is controlled by the longitudinal and orthogonal springs at the interface elements, respectively; conversely, the shear-diagonal failure is governed by the diagonal non-linear springs. The 
model has been upgraded for the simulation of the in-plane and out-of-plane behaviour of mixed systems in which the masonry interacts with beams elements [18-22].

In this study, the maximum mesh dimension was set on $1 \mathrm{~m}$, while the spacing among the springs at the interface elements was calibrated equal to $20 \mathrm{~mm}$ and $100 \mathrm{~mm}$ for the unreinforced and reinforced façade, respectively.

Since the two models, FEM and DMEM, adopt different constitutive material approaches, the mechanical parameters in 3DMacro were assessed by means of several parametric analyses. An elastic-plastic law for masonry tensile/compression (Figure 4a) was used in the DMEM to define the ductility in compression and in tension as, respectively:

$$
\mu_{c}=\varepsilon_{c r} / \varepsilon_{c e} ; \quad \quad \quad \mu_{t}=\varepsilon_{t r} / \varepsilon_{t e}
$$

The shear-diagonal spring was defined by the shear masonry modulus $G$ and the shear strength $\mathrm{f}_{\mathrm{v} 0}$ (Figure $4 \mathrm{~b}$ ). The Turnsěk and Čačovič criterion for the shear-diagonal mechanism was adopted, while the shear strength was defined dividing by 1.5 the tensile strength. Besides, parametric analyses were carried out on the ultimate shear drift, $\gamma_{u}$, in order to provide results consistent with those of the FE model. For the iron elements, the same mechanical properties implemented in DIANA were adopted (Figure 3c). The values of the mechanical parameters used for masonry and iron in the DMEM are listed in Table 2.


Register for free at https//www.scipedia.com to download the version without the watermark a) b)

Figure 4: Constitutive law in: a) tensile/compression and b) diagonal shear

Table 2: Mechanical properties used in 3DMacro DMEM

\begin{tabular}{lcccc}
\hline Parameter & & & Masonry & Iron \\
\hline Young's modulus & $E$ & {$[\mathrm{MPa}]$} & 887 & 153000 \\
\hline Tangential modulus & $G$ & {$[\mathrm{MPa}]$} & 370 & \\
\hline Compressive strength & $f_{c}$ & {$[\mathrm{MPa}]$} & 1.4 & 15.1 \\
\hline Tensile strength & $f_{t}$ & {$[\mathrm{MPa}]$} & 0.15 & 235 \\
\hline Compressive ductility & $\mu_{c}$ & - & 6.45 & - \\
\hline Tensile ductility & $\mu_{t}$ & - & 2.34 & - \\
\hline Shear modulus & $G$ & {$[\mathrm{MPa}]$} & 370 & - \\
\hline Shear strength & $f_{v 0}$ & {$[\mathrm{MPa}]$} & 0.10 & - \\
\hline Ultimate shear drift & $\gamma_{\mathrm{u}}$ & {$[\%]$} & 0.8 & - \\
\hline
\end{tabular}




\section{RESULTS OF NUMERICAL ANALYSES}

\subsection{Unreinforced masonry façade}

The study of the unreinforced façade is crucial for assessing the effects of the iron frame. One of the most important results of the non-linear static analysis is the 'capacity curve', generally expressed as the relation between the base shear and the displacement of a control point. In this case, the top point of the gable was chosen as control point.

The first interesting remark is the perfect agreement in terms of initial stiffness between the numerical curves obtained by the two approaches, as shown in Figure 5. The agreement is still satisfactory in terms of strength capacity, though a slight difference specifically due to the different modelling approach (refined and simplified models for DIANA and 3DMacro, respectively). The capacity can also be expressed in terms of the normalised base shear coefficient $C_{b}$ defined as the ratio of the base shear to the weight of the unreinforced façade (i.e., $1403 \mathrm{kN}$ ). In particular, the coefficient $C_{b}$ corresponding to the displacement of $25 \mathrm{~mm}$ is 0.71 and 0.69 for the FE and DME models, respectively.


Figure 5: Comparison between the numerical curves of the two models for the unreinforced masonry façade

Moreover, Figure 6 shows a comparison in terms of deformed shape and crack pattern, obtained by the two software at the last step of the analysis. It can be observed that similar failure mechanisms are predicted by the two models. In particular, shear and flexural failures of the masonry portions are localized above the openings and in the bottom part of the façade, respectively. 


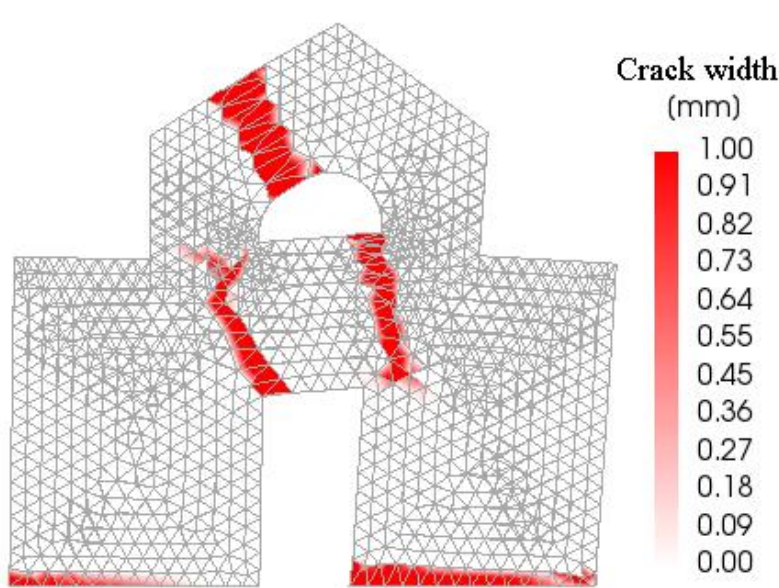

a)

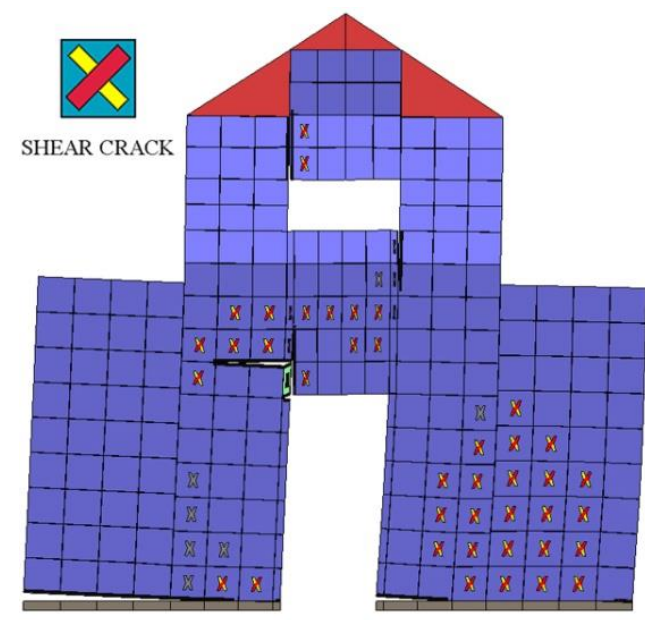

b)

Figure 6: Crack patterns on the unreinforced masonry façade: a) DIANA model; b) 3DMacro model.

\subsection{Iron 'baraccato' masonry façade}

One of the most relevant issues for the analysis of the iron 'baraccato' system is the modelling of the iron elements and their interaction with the masonry panel. Figure 7 shows the capacity curves for the unreinforced masonry façade and the iron "baraccato" façade furnished by the two software, considering the cases 1 (BEAM model) and 2 (BEAM+TRUSS model) described in section 2 As expected, an increase of both capacity reinforced façade compared to the unreinforce the "BEAM+TRUSS model" in the FEM giv difference in terms of stiffnes with respect to
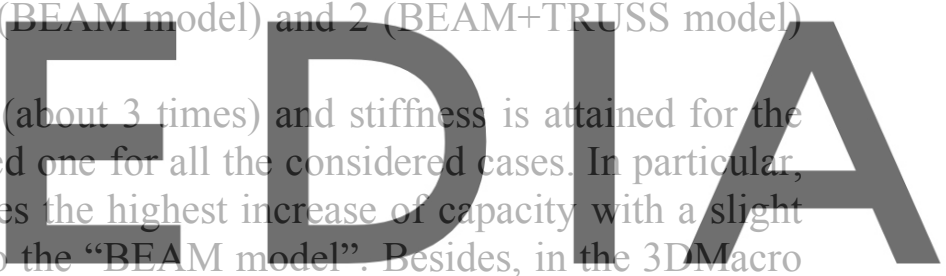

approach, the differences between "BEAM" and "BEAM+TRUSS" models are negligible, both

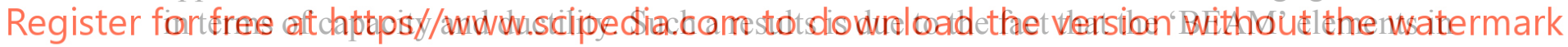
the FEM are actually able to interact with the masonry along the entire length, while in the DMEM the interaction is only restricted to the nodes of the iron frame reinforcing the structure and, thus, the interaction along the whole masonry panel is not taken into account.

Comparing the capacity curves of the two approaches, a satisfactory agreement can be observed, especially when the "BEAM" model is used. However, the maximum base shear value given by the DMEM is in the range of values provided by the FEM capacity curves.

Specifically, the coefficient $C_{b}$ related to the DME model is equal to 1.88 , which is between the minimum (BEAM) and maximum (BEAM+TRUSS) values provided by the FE model, i.e. 1.73 and 2.14, respectively. This coefficient is defined with reference to the reinforced façade weight of $1470 \mathrm{kN}$ and the ultimate displacements of the capacity curves equal to $40 \mathrm{~mm}$ and $33 \mathrm{~mm}$ for the FE and DME models, respectively (Figure 7). It is worth highlighting that both FEM and DMEM capacity curves cannot run for greater displacements due to numerical convergence issues.

Finally, Figure 8 reports the crack patterns predicted by the DMEM and FEM for the reinforced façade, in perfect agreement as well. In fact, the cracks are mainly localized in the bottom part of the façade in both approaches.

The numerical analyses have evidenced that different modelling approaches, even if 
characterized by different level of approximation, can lead to similar results both in terms of capacity curves and damage patterns. Moreover, about the modelling strategies for the iron "baraccato" system, the numerical results of the whole façade seem to be less influenced by the element type adopted for modelling the iron profiles and their interaction with the masonry panels (i.e., TRUSS or BEAM elements) in comparison with what observed in the single masonry panels investigated in [15].

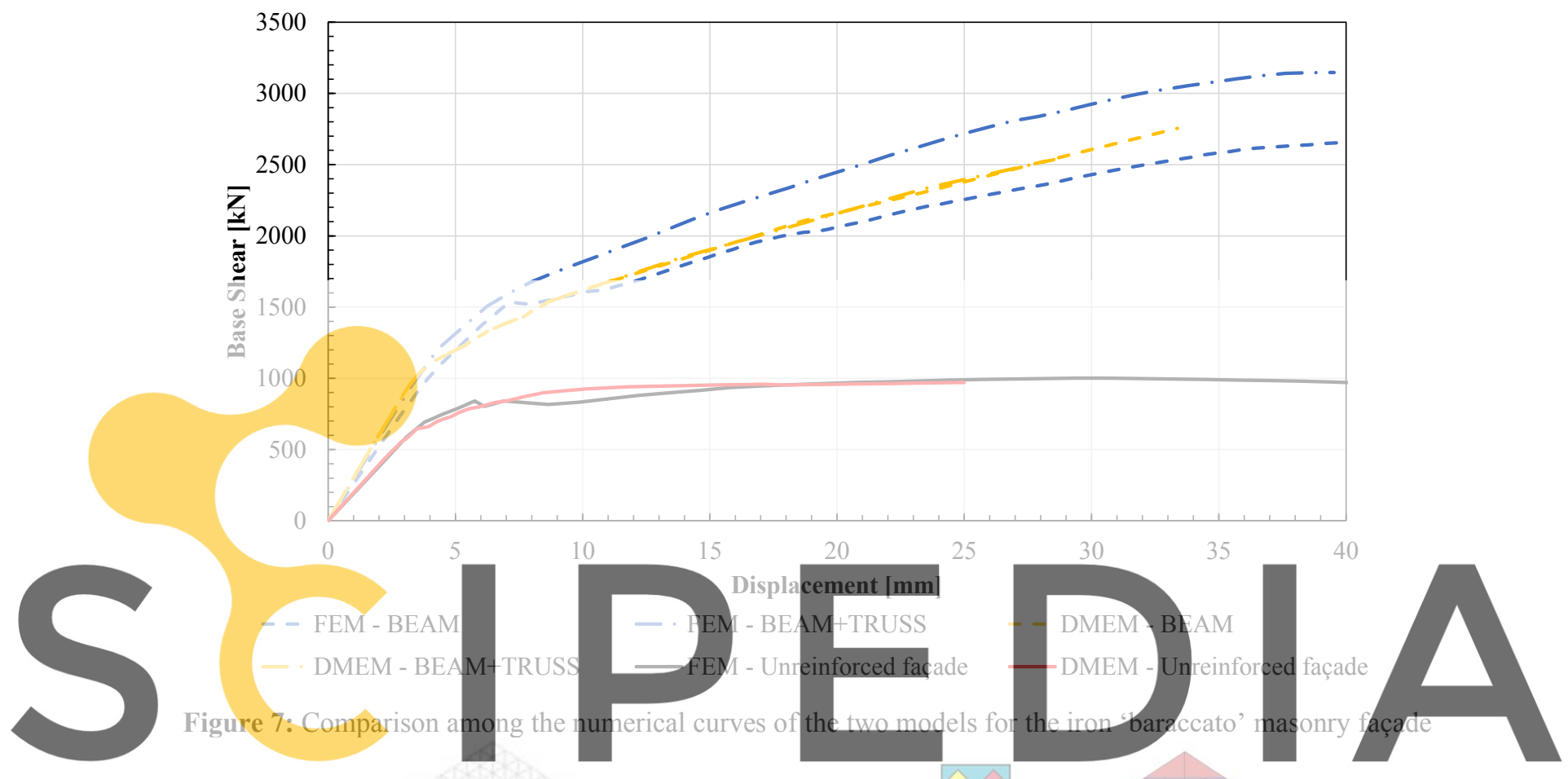

Register for free at https//www.scipedia.com to download the version without the watermark



a)

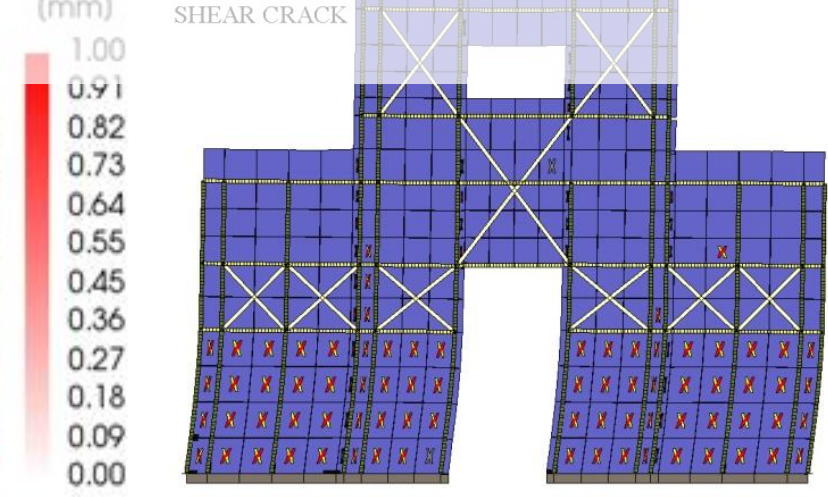

b)

Figure 8: Crack patterns in the façade with 'baraccato' system: a) DIANA model; b) 3DMacro model

\section{CONCLUSIONS}

The paper presents the results of numerical investigations on the in-plane behaviour of the façade of the Santa Maria Maddalena church, located in the Ischia Island (Italy). As part of the 
main body of the church, the façade is made of an atypical "baraccato" system consisting of a tuff masonry wall encaged by iron frames. Since few information is present in the literature regarding the iron "baraccato" system, the study was focused on the identification of the more appropriate modelling strategy for carrying out reliable numerical analyses. In particular, nonlinear analysis of the façade under horizontal actions was developed by means of a Finite Element (FE) and Discrete Macro-Element (DME) model, using the DIANA FEA and the 3DMacro software, respectively.

Firstly, the behaviour of the unreinforced masonry façade was investigated by the two approaches, also in order to calibrate the DME model on the FE one. Successively, the nonlinear analyses were extended to the same façade reinforced by means of the iron "baraccato" system. The numerical results evidenced a very good agreement between the two approaches both in terms of capacity curves and crack patterns at failure.

The influence of the modelling strategy for the iron profiles was also investigated, with reference to the hypothesis of "BEAM" or "TRUSS" element for the diagonal iron profiles. A slight difference in terms of capacity was observed in the FE model, while, in the DME one, the curves are practically coincident due to the more simplified assumptions considered for the contribute of the diagonal elements.

Despite the good agreement observed between the two approaches, a more detailed investigation on the influence of the mechanical properties on the numerical results will be developed in the future through wide parametric analyses. Successively, the examined modelling approaches will be extended to the study of the whole church taking into account both the in-plane and the out-plane response of the masonry walls.

Acknowledgements. The research has been carried out within the activities of the national Reluis project 2019-2021 "MAppe di Rischio e Scenari di danno sismico (MARS) - Task 4.8 Modelli e curve di fragilità delle chiese.

\section{REFERENCES}

[1] DIANA FEA BV. Diana user's manual, Release 10.3, (2019).

[2] Gruppo sismica S.r.1. 3DMacro. Il software per le murature (3D computer program for the seismic assessment of masonry buildings). Technical report, (2019).

[3] Ruggieri, N. The Borbone "Istruzioni per gli Ingegnieri": a historical code for earthquakeresistant constructions. Int. J. Archit. Herit. (2017) 11(2):292-304.

[4] França, J.A. A reconstrução de Lisboa ea arquitectura Pombalina. Instituto de cultura portuguesa, (1978).

[5] Hicyilmaz, K.M.O., Wilcock, T., Izatt, C., da Silva, J. and Langenbach, R. Seismic performance of Dhajji Dewari. In: 15th World Conference on Earthquake Engineering, Sociedade Portuguesa de Engenharia Sismica (SPES), (2012), pp. 24-28.

[6] Cobancaoglu, T. Himis' construction system in traditional Turkish wooden houses. In: P.B. Lourenço and P. Roca (Eds.): Structural Analysis of Historical Constructions (SAHC 2001), (2001), pp. 799-810.

[7] Kouris, L.A.S. and Kappos, A.J. Detailed and simplified non-linear models for timberframed masonry structures. J. Cult. Herit. (2012) 13(1):47-58.

[8] Cantelmi, F. Un sistema costruttivo antisismico: la casa baraccata. Geopunto (2017) 74:8- 
12.

[9] Galassi, S., Ruggieri, N. and Tempesta G. Seismic performance evaluation of timberframed masonry walls experimental tests and numerical modelling. In: N. Ruggieri et al. (Eds.): Historic Earthquake-Resistant Timber Frames in the Mediterranean Area, Springer (2015), pp. 99-103.

[10] Casapulla, C., Ceroni, F., Rainieri, C., Argiento, L.U., Arcamone, P. and Fabbrocino, G. Structural assessment of Santa Maria Maddalena church in Ischia (Italy) by experimental modal analysis under operational conditions. In: M. Papadrakakis and M. Fragiadakis (Eds.): Computational Methods in Structural Dynamics and Earthquake Engineering (COMPDYN 2019), ECCOMAS Bookseries (2019), pp. 1-14.

[11]Di Napoli, B. Modelling and safety assessment of the Santa Maria Maddalena Church, Ischia, Italy. Msc. Thesis, Universidade do Minho, Portugal, (2019).

[12]Ceroni, F., Pecce, M., Voto, S. and Manfredi, G. Historical, architectural and structural assessment of the Bell Tower of Santa Maria del Carmine, International Journal of Architectural Heritage: Conservation, Analysis, and Restoration, Francis Taylor, Vol. 3, Issue 3, (2009), pp. 169-194.

[13] Brussel, M.N. Appraisal of existing iron and steel structures. The Steel Construction Institute, Ascot -Berkshire, (1998).

[14] Ministero delle Infrastrutture e dei Trasporti. NTC 2018 - Norme Tecniche per le Costruzioni di cui al D.M. 17/ 01/2018. Italy: Gazzetta Ufficiale N. 42 del 20/02/2018 (2018). (in Italian)

[15] Celano, T., Argiento, L.U., Ceroni, F. and Casapulla, C. In-plane behavior of iron-framed masonry panels: numerical analyses. In: T.P. Tasios et al. (Eds.): 4th International Conference on Protection of Historical Constructions (PROHITECH 2020), (2020).

[16]Caddemi, S., Caliò, I., Cannizzaro F. and Pantò, B. New Frontiers on Seismic Modeling of Masonry Structures" Frontiers in Built Environment (2017) 3, 39.

[17] Lourenço, P.B. Structural masonry analysis: Recent developments and prospects. In: M. Masi et al. (Eds.): Proceedings of the 14th International Brick \& Block Masonry Conference, University of Newcastle (2008), pp. 1341-56.

[18] Caliò, I., Marletta, M. and Pantò, B. A new discrete element model for the evaluation of the seismic behaviour of the unreinforced masonry builings. Eng. Struct. (2012) 40:327338.

[19] Chácara, C., Lourenço, P.B., Pantò, B., Cannizzaro, F. and Caliò, I. Parametric numerical studies on the dynamic response of unreinforced masonry structures. In: K. Van Balen and E. Verstrynge (Eds.): Structural Analysis of Historical Constructions (SAHC 2016), CRC Press (2016), pp. 239-245.

[20]Caliò, I. and Pantò, B. A macro-element modelling approach of Infilled Frame Structures. Comput. Struct. (2014) 143: 91-107.

[21] Pantò, B., Caliò, I. and Lourenço, P. B. A 3D discrete macro-element for modelling the out-of-plane behaviour of infilled frame structures. Eng. Struct. (2018) 175: 371-385.

[22] Pantò, B., Silva, L., Vasconcelos, G. and Lourenço, P. B. Macro-modelling approach for assessment of out-of-plane behavior of brick masonry infill walls. Eng. Struct. (2019) 181: 529-549. 